Peer review: This article has been subject to a double-blind peer review process

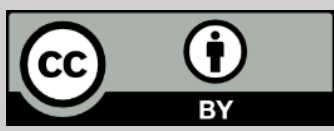

Copyright notice: This article is issued under the terms of the Creative Commons Attribution License, which permits use and redistribution of the work provided that the original author and source are credited.

You must give appropriate credit (author attribution), provide a link to the license, and indicate if changes were made. You may do so in any reasonable manner, but not in any way that suggests the licensor endorses you or your use. You may not apply legal terms or technological measures that legally restrict others from doing anything the license permits.

https://creativecommons .org/licenses/by/4.0/

\section{The Social Stigma and the Challenges of Raising a Child with Autism Spectrum Disorders (ASD) in Greece}

\author{
Eirini Veroni \\ Centre for Education Studies, University of Warwick \\ *Correspondence: E.Veroni@warwick.ac.uk
}

\begin{abstract}
This paper describes the social stigma and the challenges some Greek parents of children with autism spectrum disorders (ASD) ${ }^{1}$ faced in Athens, Greece. The sample consisted of seventy-four parents of children with ASD and a mixed methods approach was used; (seventy - four parents completed a semi - structured questionnaire and twenty had semistructured interviews). The quantitative and qualitative findings show these parents and families of ASD children experienced stigma in various ways which played a major role in making their lives difficult. This study offers a lens through which to view attitudes towards disability, stigmatisation, especially when resources are scarce. It was conducted in Greece during the period of austerity, affecting the delivery of education within social - cultural restraints. So studies at a different time or in another place could produce other findings.
\end{abstract}

Keywords: autism spectrum disorders (ASD); Greek parents; social stigma; austerity; open-ended questionnaires; social isolation

\section{Introduction}

The serious financial and economic crisis in Greece has affected the services provided to children with autism spectrum disorders (ASD) (Kalyva, 2013; Stampolis et al., 2012; Syriopoulou - Delli et al., 2012). The reduced economic capacities post-crisis, at both state and family levels, continue to prevent these children from fully enjoying their constitutional rights to inclusive education, quality health services and effective social care structures (Policy Department C, 2013). Greek Social Services have been described as unavailable, difficult to obtain, inappropriate and inaccessible (Kalyva, 2011; Stampolis et al., 2012; Syriopoulou-Deli et al., 2012). The Committee for the Rights of the Child in Greece recommended investment to protect vulnerable children, including children with disabilities, by defining strategic budgetary lines to be protected even in situations of economic crisis (Policy Department C, 2013). 
This study aimed to shed light on the challenges that parents, and families face in supporting their children with disabilities in an age of austerity with welfare services curtailed. This paper is based on a previously published conference paper describing my doctoral research.

Karim et al., (2012) and Ridge (2013) have argued that families with disabled children are the worst hit when resources are restricted. Hartas claims neoliberal policies make parenting harder because the legitimacy of the state's support for structural inequality is questionable and so responsibility for overcoming structural problems and the unequal provision of adequate services to children rests with the family itself (Hartas, 2014). Cuts to social benefits over the last decade have had a severe financial impact on most families, especially those with disabled children, and some young people's educational, social and physical needs have not been met (Ridge, 2013). Living with a child diagnosed with ASD poses many challenges for a family. Generally, parents are told to let the professionals organise interventions to support their child. However, insufficient resources and training, and lack of scientifically-based practice approaches have left many parents dissatisfied with the services provided and children not achieving their full potential, leaving families exposed to tremendous stress.

Their stress is increased by social stigma, which has not been extensively researched in Greece because of the economic crisis, nor have the difficulties stigma adds to other challenges these families face. Parents with children in the autism spectrum disorder are more at risk of developing depression and other mental disorders than parents of children with other disabilities (Benson \& Karlof, 2009; Ekas et al., 2010). Many questions arise about the relationship between autism spectrum disorder and the mental health of parents, particularly the mechanisms that link ASD to anxiety and depression found in parents (Cramm \& Nieboer, 2011; Meirsschaut et al., 2010). Heiman's (2002) survey suggests that inadequate knowledge of ASD in relation to other disabilities and the socially undesirable and aggressive behaviour of children with this disorder seem to cause anxiety and depression in parents.

Three anxiety factors linked to the upbringing of a child with autism are the permanence of the situation, the lack of acceptance of autistic behaviour by society (and often the family itself) and the low levels of social support (Konstantareas \& Homatidis, 1989; Twoy et al., 2007). In Greece, these factors have not been extensively investigated; this research will address this lack, focusing on social stigma. 
Much of the previous research into parental caregivers' emotional and physical health centred on their children's behavioural problems or hoe severe their disability was (e.g. Plant \& Sanders, 2007) rather than lack of support (Resch et al., 2010). The number of children diagnosed with ASD continues to rise, while resources decline or are insufficient to support parents and families (Hall \& Graff, 2011).

Understanding what parents go through is essential to the design of appropriate interventions to reduce parenting stress and empower the parents of ASD children by helping them access the available sources of social support and provide strategies to cope with stigmatisation (Dardas, 2014; Hope-West, 2011). Most studies reviewed employed qualitative methods, mainly interviews with teachers (e.g. Hoogsteen \& Woodgate, 2013; Ingersoll \& Hambrick, 2011) rather than quantitative or mixed methods. This research took a mixed method approach of questionnaires and interviews with parents. The research questions were:

1. Do Greek parents of children with ASD face social stigmatisation?

2. Do Greek parents of children with ASD face social-emotional isolation?

\section{Autism in the Greek educational system}

Much of the research into special educational needs (e.g. Gray, 2003; Hutton \& Caron, 2005; Montes \& Halterman, 2007; Tomanik et al., 2004) discusses the difficulties parents of ASD children face in their daily lives. Glover-Graf (2011), suggests parents are likely to experience strained marital and extended family relations, social isolation, challenging education arrangements, and a sense of grief related to the restricted opportunities of their children. A diagnosis of ASD affects not only the diagnosed individual, but their entire family. Parents will have to advocate on behalf of their children, identify their needs, recognise their strengths, challenge practices and negotiate to participate in decision - making with the professionals, express dissatisfaction to providers, and reach resolutions regarding all these concerns.

Parents have the greatest influence on the outcomes for their children with ASD (Wang, 2008; Singer et al., 2012). Beatson (2008), Beckman (2002), and Prelock et al. (2003) highlight the importance of the interaction between families and professionals. The increase in diagnoses of autism spectrum disorder has resulted in the creation of a special needs category - Greek education laws 1566 (1985) and 2817 (2000). In 2008, a new education law (3699) specified that children with autism spectrum disorder were to be placed in line with their cognitive and language abilities and social skills (Makrygianni \& Reed, 2010; Miller et al., 2013; Syriopoulou-Deli, 2010). No comprehensive official statistics on the exact 
number of Greek people with ASD exist (Centre for Education Research, 2009). Keennan et al., (2015, p. 173) claim the lack of adequate Applied Behaviour Analysis $(A B A)^{2}$ support means the different needs of individuals may not be taken into account. Law 3699 (2008) explicitly makes the state responsible for special education as an integral part of mandatory, free public education and free special education and training for individuals with disabilities of any age and at all education levels. The state is also committed to supporting their full inclusion participation and contribution to society, independent living, economic self-sufficiency and autonomy.

No suggestions are offered as to how these aims will be met, as no legislation in Greece targets ASD specifically, only the education and treatment of all children with special needs. The newer ABA approach is not mentioned in any official document. The traditional eclectic interventions by psychiatrists, psychologists, speech and language therapists, special educators and occupational therapists are often prescribed and partly funded by the public health system in educational or home settings (Ministry of Interior, 2007).

Kalyva (2013) and Stampoltzis et al.'s (2012) empirical studies exploring the needs of children with ASD in Greece found the Greek government's financial support for parents of children with ASD and professionals for training and professional development was inadequate. In addition, very few secondary schools in Greece had the curriculum content, teaching accommodation and/or adequately trained personnel appropriate to the needs of ASD children.

Kalyva (2013) claims Greek parents of children with ASD are not content with the facilities offered in formal educational settings (special schools). Gena et al. (2006) claimed Greek families suffer due to the under-funding of appropriate educational provision for their ASD children. Few empirical studies in Greece have examined contextual factors such as parents' involvement with their children's learning, parent - professional cooperation, the types of service offered in special education settings, the lack of public services and the generally limited resources within ASD education provision and the impact these have on social relations. A few studies (e.g. Avramidis \& Kalyva, 2007; Konstantareas \& Homatidis, 1989; Mavropoulou, 2007; Papageorgiou \& Kalyva, 2010) have examined parents' needs but paid scant attention to the support services available for families with ASD children or the challenges parents face in looking after and educating their children. 


\section{Challenges faced by parents raising children with ASD: parents' emotional wellbeing}

Living with a child diagnosed with ASD challenges parents who are often themselves at risk of developing negative psychological outcomes including high levels of stress (Griffith \& Hastings, 2010; Ingersoll \& Hambrick, 2011; Ludlow et al., 2012).

Problems often result from a mismatch between parents' needs and the resources available which could be effectively addressed by policy makers and service providers collaborating with families to identify needs and establish family-centred policies and services to meet them (Prelock \& Hutchins, 2008; Resch et al., 2010). International research indicates that caring for a child or adult suffering from a developmental disorder demands superlative parental care which adds to their burden of stress (Dyson, 1997; Hassal et al., 2006; Hayes \& Watson, 2012; Ludlow et al., 2012; Myers et al., 2009; Whitaker, 2002) because a wide range of symptoms can be part of their disability (Griffith \& Hastings, 2010; Ingersoll \& Hambrick, 2011; Konstantareas, 1990; Montes \& Halterman,2007; Woodgate et al., 2008).

\subsection{Social Stigma}

The term stigma is used in the sense of disapproval by and exclusion from a social group when an individual's behaviour does not accord with its rules (Whitehead, 2001). Most people, according to Goffman (1963; 1986) consider the stigmatised person as abnormal, even as non-human. At best, the stigmatized are considered human but incomplete, which can be presented as the justification for discrimination, both painful and inhibiting for the stigmatized individual's development. Hostile reactions can be seen by the 'normal' as justified by the phobias and the fear they face in encounters with these individuals (Goffman, 2009). Goffman (1963; 1986) also points out that the near environment of family and friends usually supports the stigmatised and, accepts them, albeit not in all cases.

Green et al. (2005: p.197) refer to Link and Phelan's earlier (2001) work labelling as a way of denoting difference or by ignoring those who are different in social situations, seeing biological difference as being socially significant. Green (2003) defines stereotyping as the attribution of negative value to socially silenced differences.

Link and Phelan (2006) add that the sources and targets of stigmatization are two different concepts; felt and enacted stigma. Felt stigma relates to the feelings of those with a socially undesirable attribute while enacted stigma relates to discrimination against those who have a stigmatizing 
attribute. Parker and Aggleton (2003) suggest enacted stigma produce and reproduces the existing social hierarchies and resisting or negotiating the experience of felt stigma is a way of challenging these hierarchies.

\subsubsection{Social stigma and Autism Spectrum Disorders}

Stigma associated with ASD is significant and widespread. Kinnear et al. (2016) suggest the need for research into the parents of children with ASD to further understand the components and impact of stigma on their lives. Stigma is a multifaceted construct, according to Goffman (2009), deeply discrediting since it turns the individual from a whole person into a tainted, discounted one. Wachtel and Carter (2008) argue that when a child is diagnosed with ASD, parents experience a range of feelings and a set of challenges that impact on their psychological adjustment, ranging from relief because their suspicions were validated, to grief for the loss of a life the way they had envisioned. Gray (1993) adds Goffman's (1963; 1986) courtesy stigma or stigma by association to refer to those who voluntarily associate with stigmatized individuals. Lilley (2013) includes parents among the circle of people she calls "wise" in the sense that they are "intimate with and privy to the daily lives and social worlds of those who are stigmatised" (Lilley, 2013, p.4), and so become stigmatised themselves through this connection. Gray (2002) found stigma by association applies to the parents of autistic children and highlighted the situations that provoke stereotyping and facilitate stigmatisation: the differences between the external appearance of children with ASD and the reality of their condition; the distinctive, disruptive, and socially inappropriate behaviour that children with ASD exhibit; the hardship that parents experience trying to get an accurate diagnosis.

Farrugia (2009) argues that parents have difficulty connecting with their child diagnosed with ASD, wanting to detach themselves from feeling they have "a spoiled identity". Moreover, Green et al. (2005) offer Susman's (1994) definition of stigma "as an adverse reaction to the perception of a negatively evaluated difference" (Green et al., 2005, p.197). Here, stigma comes from the interaction between the stigmatised individual and those who evaluate difference negatively, what Green (2003) refers to as the subjective burden of stigmatization, relating it to feelings caregivers experience in coping with other's reactions to children with disability. Green identified a range of emotions: "embarrassment, guilt, shame, resentment, entrapment, worry" (Green, 2003, p.1364).

Gray $(1993 ; 2002)$ investigated courtesy stigma as experienced by the parents of children diagnosed with ASD, arguing that mothers experience stronger feelings of stigmatization than fathers as they "take greater responsibility for the public presentation of the family" (Gray 1993, p.114). Green (2003) also suggests that "the degree of stigma expected by 
mothers has an impact on the emotional and social outcomes for themselves and their children" (Green, 2003, p.1371), while Brobst et al. (2009) point out common themes in research regarding the difficulties of parenting a child with special needs include fathers' lesser involvement in child care.

Parish et al. (2004) point out that the needs of children with developmental disabilities' range from specific therapies, respite care, complex diagnostic tests, modifications to their homes, equipment, adapted to their requirements medication, and special educational services, all of which entail financial difficulties, loss of employment and lack time for parents' personal needs.

Link and Phelan (2001) discuss stigma in the context of interrelated power differentials, including loss of status, when stigma prevents the individual from fully participating in the social and economic life of the community. Lilley (2013) argues that the problem is partly due to inadequate state support and services for the developmentally disabled; consequently, one parent has to be available at all times to look after their child, negotiate and advocate with service providers for their child's needs, and so is vulnerable to being stigmatised.

Link and Phelan (2006) describe how parents face a form of exclusion in trying to enrol their child if the school they want does not have the necessary resources to help them. Such exclusions happen often enough to be considered practices stigmatise ASD children (Link \& Phelan 2001, stated in Lilley, 2013). These difficulties combined with social stigma, one of their most difficult aspects of public confrontation (Davies \& Hall, 2005; Guralnick et al., 2008), mean Greek families and parents often perceive society's reaction to their child's disability as stereotypical and negative (Papageorgiou \& Kalyva, 2010; Patistea \& Patistea-Tavoularea, 2009).

\section{Methodology}

\subsection{Research Design}

The research language was Greek, and the author translated the methodological tools and results into English. Purposive sampling strategy (Patton, 2002) was used to select seventy-four parents whose children had been diagnosed ASD. The fieldwork was carried out in three (one urban, two suburban) special (SES) schools for children with ASD, all of mixed socioeconomic-status (SES) and three Centres for Differential Diagnosis and Support of Special Educational Needs (K.E.D.D.Y) ${ }^{3}$ Centres located in the Attika region, urban and suburban. 
These settings were selected because multidisciplinary teams were there conducting assessments and supporting children with ASD. The mixed methods sequential exploratory design had two phases; quantitative questionnaire responses, open qualitative questions (see Appendix) then individual interviews, also qualitative. In this way, "the quantitative data and its subsequent analysis provide a general understanding of the research problem. The qualitative data and their analysis refine and explain the statistical results by exploring the participants' views in more depth" (Punch, 2011, p.300).

\subsection{Participants' Profiles (Questionnaires)}

The 74 parents had lived in Greece for most of their lives, were raising their children in Greece and were the biological parents of at least one child diagnosed with DSM-5 Autism Spectrum Disorder. Their children were aged 7 - 17 years old (when ASD diagnosis is easier) and, diagnosed with ASD by a registered child psychiatrist and were enrolled in either a primary or secondary state school. No real names are used to protect their privacy.

The demographic characteristics of the 74 are: most were mothers (70.3\%) who had completed basic education $(47.3 \%)$ and married $(85.1 \%)$. The sample had 53 mothers (71.6\%) and 21 fathers (28.4\%). Most of the children with ASD were male, 58 boys (78.4\%), 16 girls (21.6\%). The questionnaire, in addition to personal and demographic information, asked whether there were other autistic children in the family and if their child with ASD presented other medical issues, as shown below (tables 13).

Table 1: Sample Gender \& Marital Status

\begin{tabular}{|c|c||c|c|c|c|}
\hline \multicolumn{2}{|c||}{ Gender } & \multicolumn{4}{c|}{ Marital Status } \\
\hline Male & Female & Single & Married & Divorced & Widowed \\
\hline $29.7 \%$ & $70.3 \%$ & $1.4 \%$ & $85.1 \%$ & $8.1 \%$ & $5.4 \%$ \\
\hline \multicolumn{2}{|l|}{ Sample size: $n=74$} & & & & \\
\hline
\end{tabular}

Table 2: Parents' Educational level

\begin{tabular}{|c|c|c|c|}
\hline Lyceum & University & $\begin{array}{c}\text { MA or PhD } \\
\text { holders }\end{array}$ & Other \\
\hline $47.3 \%$ & $35.1 \%$ & $14.9 \%$ & $1.4 \%$ \\
\hline Sample size: $n=74$ &
\end{tabular}


Table 3: Other Medical Issues for Children with Autism within Sample

\begin{tabular}{|l|c|}
\hline Language and speech problems & $70 \%$ \\
\hline Balance and coordination problems & $18.3 \%$ \\
\hline Hearing Problems & $5 \%$ \\
\hline Feeding Problems & $30 \%$ \\
\hline Clumsiness & $25 \%$ \\
\hline Other & $12.2 \%$ \\
\hline Sample size: $n=74$ & \\
\hline
\end{tabular}

\subsection{Measures}

The questionnaire used a Social Stigma Scale adapted from the Impact on Family Scale (Stein \& Jessop, 2003) and the Professional Autism Needs Questionnaire (PAN-Q) (see Keenan et al., 2007) measuring five items (i.e. prejudice, stereotyping, bullying, public awareness of ASD, society labelling the child as 'disobedient'). The participants selected 'yes' or 'no' for experience of each. Some open-ended questions (see Appendix) were included in this questionnaire and later, twenty parents were interviewed to allow them to expand on their answers or introduce other relevant issues.

\subsection{Procedure}

100 questionnaires were delivered to the participants by hand in order to maximize the return rate. This research complies with the guidelines of the British Educational Research Association (BERA, 2011). Official approval was obtained from the Special Education Department of the Ministry of Education in Greece. The participants were also told, as they were volunteers, they were free to leave the project at any point. Prior to the research, the participants had provided written consent and been made aware of the nature of the research. The participants were also informed that their cultural values would be respected and that their responses kept anonymous. 


\section{Results}

\subsection{Social stigma}

Around half the parents indicated they had experienced negative stereotyping or prejudice according the Social stigma scale. About 36.5\% of parents indicated their child had been stigmatised as 'disobedient' and $18.9 \%$ stated their children had experienced bullying. However, $64.9 \%$ of parents felt the level of public awareness of ASD was high which is encouraging. Most parents faced challenging behaviour from their child (aggression, tantrums, stereotypical behaviour, self-injury behaviour, being withdrawn and socially inappropriate behaviour) (see Figure 1).

Figure 1: Occurrence of Social Stigma ( $n=74$, parents of children with ASD)

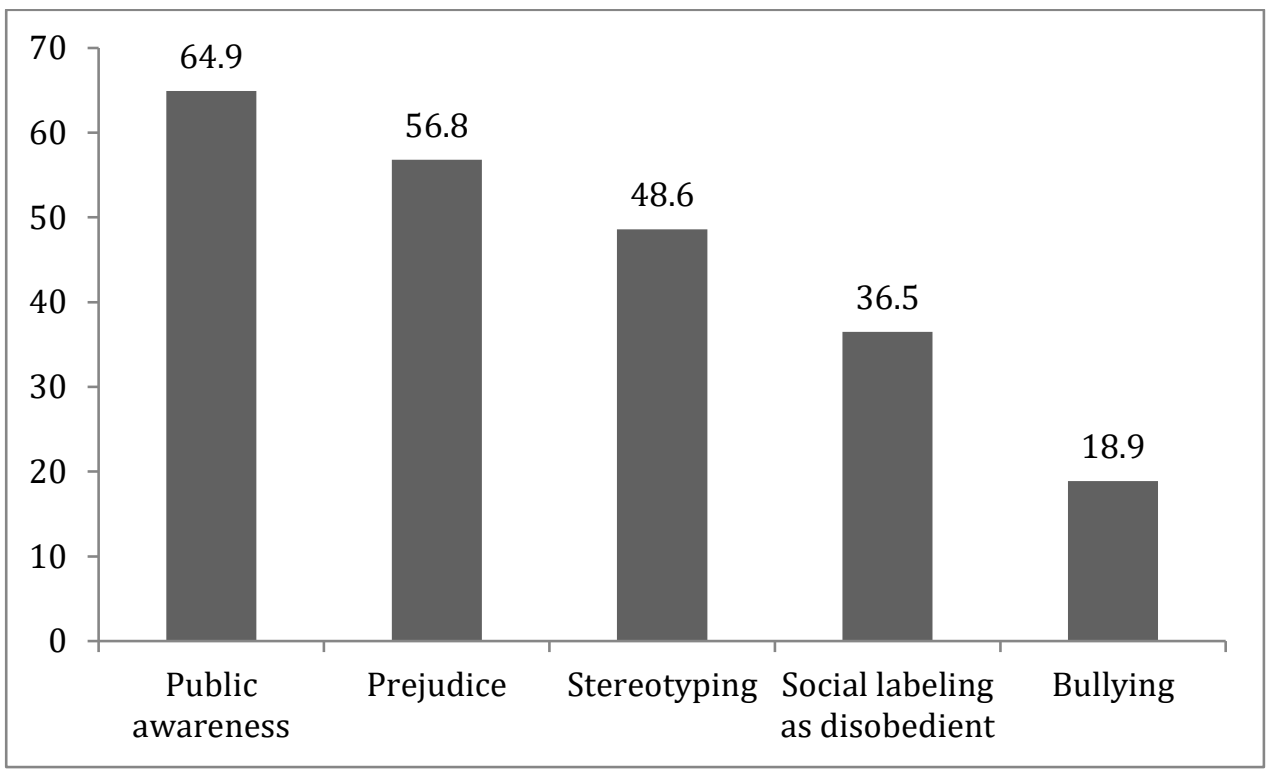

Green et al. (2005) argued that the majority "of research on caring for children with disabilities has emphasized the emotional distress of having a child with a disability and de-emphasized both the benefits of caring for a child with a disability and the negative consequences of stigma and socio-structural constraints". (Green et al., 2005, pp. 158 - 160). They also claim that if emotional distress persists, it is due to the belief that disabled people are the objects of social stigmatization and not related to degree of disability.

Table 4 shows that social stigma is not related to the parents' education level, that the severity of social stigma can be a problem for all socio economic levels of Greek society. 


\begin{tabular}{|c|c|c|c|c|c|c|c|c|c|c|c|c|c|c|}
\hline & \multicolumn{4}{|c|}{ Lyceum graduate } & \multicolumn{4}{|c|}{ University graduate } & \multicolumn{4}{|c|}{ Master or PhD degree } & & \\
\hline & \multicolumn{2}{|c|}{ No } & \multicolumn{2}{|c|}{ Yes } & \multicolumn{2}{|c|}{ No } & \multicolumn{2}{|c|}{ Yes } & \multicolumn{2}{|c|}{ No } & \multicolumn{2}{|c|}{ Yes } & \multirow[b]{2}{*}{$X^{2}(2)$} & \multirow[b]{2}{*}{$p$} \\
\hline & $\mathrm{N}$ & $\%$ & $\mathrm{~N}$ & $\%$ & $\mathrm{~N}$ & $\%$ & $\mathrm{~N}$ & $\%$ & $\mathrm{~N}$ & $\%$ & $\mathrm{~N}$ & $\%$ & & \\
\hline Prejudice & 13 & $37.1 \%$ & 22 & $62.9 \%$ & 12 & $46.2 \%$ & 14 & $53.8 \%$ & 5 & $45.5 \%$ & 6 & $54.5 \%$ & .575 & .750 \\
\hline Stereotyping & 19 & $54.3 \%$ & 16 & $45.7 \%$ & 12 & $46.2 \%$ & 14 & $53.8 \%$ & 6 & $54.5 \%$ & 5 & $45.5 \%$ & .447 & .800 \\
\hline $\begin{array}{l}\text { Public } \\
\text { awareness of } \\
\text { condition }\end{array}$ & 14 & $40.0 \%$ & 21 & $60.0 \%$ & 7 & $26.9 \%$ & 19 & $73.1 \%$ & 4 & $36.4 \%$ & 7 & $63.6 \%$ & 1.141 & .565 \\
\hline \begin{tabular}{|l|} 
Society \\
labelling \\
your child as \\
'disobedient; \\
or 'ignorant'
\end{tabular} & 23 & $65.7 \%$ & 12 & $34.3 \%$ & 16 & $61.5 \%$ & 10 & $38.5 \%$ & 7 & $63.6 \%$ & 4 & $36.4 \%$ & .113 & .945 \\
\hline Bullying & 28 & $80.0 \%$ & 7 & $20.0 \%$ & 23 & $88.5 \%$ & 3 & $11.5 \%$ & 8 & $72.7 \%$ & 3 & $27.3 \%$ & 1.467 & .480 \\
\hline $\begin{array}{l}\text { No } \\
\text { challenges }\end{array}$ & 32 & $91.4 \%$ & 3 & $8.6 \%$ & 22 & $84.6 \%$ & 4 & $15.4 \%$ & 9 & $81.8 \%$ & 2 & $18.2 \%$ & 1.016 & .602 \\
\hline
\end{tabular}

Note: primary school and high school were excluded from the analysis, as there was a very small sample for these categories

Most of the 20 parents interviewed felt prejudice and stigma to be a significant obstacle in their lives. They reported rejection and struggles against discrimination. Twelve parents claimed they felt lonely and isolated because of being socially rejected while another actually experienced being socially excluded. Others claimed to have lost friends, while ten experienced limitations to their social lives. Seven parents experienced local rejection and stigmatisation, and also within themselves. Eight parents had asked local people to rethink their attitude to disability and accept people who were different. The interviewees indicated their relationship with the world involved indifference or compassion, or the need to explain the inexplicable behaviour of their child, that society's attitude to ASD is influenced by prejudice and stigma, resulting in isolation and discrimination against the child with ASD.

"I feel a gross injustice because people don't understand, and they don't accept my child's particularity" (a father's comment)

The various qualitative data of all participants was analysed using thematic analysis. Thematic analysis is a fundamental method of qualitative analysis and suggested by Braun and Clarke (2013) appeared to be the most feasible way of analysing the interview transcripts of this research to thematise the participants' experienced world. 


\subsection{Social - Emotional Isolation and Social Networks}

Due to their communication and social interaction difficulties, children with autism exhibit behaviours that are disruptive and hard to manage. These behaviours are not only a source of stress for parents but can make them feel extremely isolated.

According to the interviewees' responses, outside the home, the parents and families of ASD children often have problems controlling or disciplining them. Parents were the butt of unhelpful or abusive remarks outside the home as a result of their children's behaviour, when other people were around in places like churches, playgrounds, restaurants or when shopping. A few parents felt angry after unhelpful or aggressive remarks or about the behaviour of their children. Many parents reported having a normal social life challenging. They wanted their children to make friends and be accepted by others. They found it very painful for them to see their child rejected by others. Many suffered bouts of anxiety. The mainstream or special school can play an important role in improving social interactions with peers.

"It was a shock when the private kindergarten did not allow my child to participate in a school celebration, so as not to spoil or offend the parents of normal children" (a mother's comment)

The majority of parents experienced isolation due to their children's behaviour in a social environment. They felt a self-help social network of parents with ASD children could help the exchange of ideas, opinions and experiences in an environment friendly to their child as a way forward.

"We share our experience with our social environment because we want to include our child in it. We believe that it will be really helpful for him to be a member of our society" (a father's comment)

The interviewees acknowledged that other people can offer emotional support for their children with ASD; some shared feelings with their extended family and friends who also had children with ASD. The parents of ASD children need strong coping skills and informal support to reduce stress and deal with the social and psychological felt effects of stigmatisation. 


\section{Discussion and Implications}

The social stigma parents of children with ASD $^{5}$ face and their needs and expectations were identified through questionnaires and interviews. $A$ child with ASD creates challenges to family life and inter-familial relationships, which emerged from both quantitative and qualitative data about parents' everyday experiences of living with a child with ASD and the knowledge they acquired through trial and error.

Stigma played a major role in making life difficult for the parent/respondents of children with ASD. They worried about being treated differently, were ashamed or embarrassed by their child's condition or even tried to keep their child's condition a secret.

Greek parents of children with ASD face many trials, two of which are stigmatisation and lack of the appropriate provision for their child. The interview data revealed parents' concerns that their children behaved in non-age appropriate developmental ways and that the child they now had to raise is "different to the one they gave birth to", suggesting that some parents themselves could view their child as transgressing the dominant ideas of normal behaviour (Huws \& Jones, 2010) and thus as stigmatised objects.

Parents in this study highlighted the need for professional and personal networks that could provide social support to help them work through societal prejudice and stigma. For the researcher, the value of this research lies in helping the voices of parents to be heard.

The questionnaire results suggest many Greek parents experienced negative stereotyping and prejudice, but only $35.1 \%$ felt public awareness of ASD was low. The most difficult to cope with social stigmatisation pertained to the nature of the condition, while more than half the parents saw prejudice as the major obstacle they have to overcome. Klar-Wolfond (2006) claims that better knowledge and understanding of $A_{S D}^{6}$ will lead to greater respect, dignity, tolerance and support from the community, but the stigma attached to autism and the lack of understanding of it by the public put's parents under considerable levels of stress (Ming, 2006, pp. 47-49) as experienced by the interviewees. They reported feeling that sometimes others blamed them for their child's difficult behaviour or perceived the child's behaviour as a reflection of their parenting skills, as in Lubetsky et al.'s findings (2011). Cosser's findings (2005) also showed that parents felt blamed for their child's behaviour and, in addition, some parents had blamed themselves before they were given their child's diagnosis. This study's findings are consistent with other findings (e.g. Broady et al., 2015; Gray, 1993; Gray, 2002; Green, 2003; Green et al., 2005; Kinnear et al., 2016) that indicate the majority of parents 
experienced felt stigma, which relates to the feelings associated with having a socially undesirable attribute.

The quantitative and qualitative findings indicate that the study parents of children with ASD felt what Green refers to as "internal turmoil experienced on a regular basis" (Green 2003, p.1366) due to the burden of stigmatization and the everyday tasks required to care for their children. The parents in this study experienced the felt, enacted, and courtesy stigma (outlined in Section 3 ) due to their child's condition.

Gray (1993) and Green (2003) argue that mothers experience stronger feelings of stigmatization than fathers and Brobst et al. (2009) point out that fathers tend to have less involvement in caring for a child with special needs. Whether stigmatization is differently experienced by mothers and fathers is not clear, but the findings from this study also indicated that the majority of prime caregivers were mothers who had completed studies at university level and substantiate Gray's research (1993; 2002).

Parents in this study seemed to experience the "structural discrimination" described by Link and Phelan (2006) when they tried to enrol their child at school and the school, they wanted their children to attend did not have the resources needed to help their children, but also because of the prejudiced attitudes of other parents. According to the findings, such attempts at exclusion occurred often enough to disadvantage children with ASD (Link \& Phelan 2001, as stated in Lilley, 2013).

Parents argued that they were labelled and stereotyped by their social circle, and in response they tried to be frank and educate "others" about their child's condition. The participants claimed they felt inadequate as parents since their child was not able to achieve "the persuasive grip" of other children (James, 2005, pp.102-103) and also because they focused their attention on the child with ASD, neglecting any siblings:

"I experienced a mournful situation. It got so bad I became jealous of my own children on behalf of my child with ASD. This was a serious issue, so I wasn't interested in my other children and didn't pay attention to their needs either. I was absorbed with my son. I slept and woke up with his image. My son was my hope" (a mother's comment)

The qualitative (interview) data revealed some parents experienced marginalization because their children would never reach the expected childhood milestones. They felt they belonged to a group of "us against the rest" as Lilley (2013) describes it and had to act as mediators for their children to minimize societal stigma. 
As pointed out, the qualitative findings in this study indicate parents also experienced courtesy (by association) stigma; their responses suggest they had experienced all the attributes of stigma indicated in Gray's (2003) research.

"Besides our efforts to accept our child's particularity we also face problems with our child's development. A significant obstacle is the attitude of the state and the whole society which doesn't realise that everyone is different with a unique personality and different needs" (a father's comment)

Parents' responses seemed to support Farrugia's (2009) findings of the parent-child relationships being seen in terms of disability as well as autism because their child's diagnosis made it difficult for parents to connect with him/her as they wanted to detach themselves from feelings of having "a spoiled identity". The interview data indicated that parents had to find new ways of communicating with their children while holding on feelings of "normal but different" Gray (1993).

The data in this study show the experience of stigma is related to the lack of services for ASD children to meet their educational and social needs. Parents struggled to obtain equality in education and services while facing the absence of the necessary technical infrastructure, understaffing in schools, lack of funding, covert or overt practices of acceptance and/or rejection of people with disabilities in the education system (Loukisas \& Papoudi, 2016). Most parents acknowledged that they felt victims of the current situation in Greece and shared their emotional burden only with their immediate family. Their difficulties remain in the private sphere of the family because they face societal prejudice and rejection. Thirteen out of twenty interviewed parents experienced a sense of victimisation and helplessness:

"Our children are the children of a lesser God. If my child lived in any other country of Central and Northern Europe, he would have another process in his life. In Greece, we are intruders, the government isn't interested in our children" (a mother's comment)

According to Hartas (2014) the privacy of family life should be guarded as the last refuge of parents and family members and function as a "buffer" between their children and the state to protect them from exploitation and oppression (p. 135). This was difficult to achieve according to the interviewees, since lack of social support and the stress of living with autistic individuals can affect the psychological wellbeing of the whole family (Gray, 1993, p.103). 
Parents' emotional challenges particularly stigmatisation emerged as a key issue in this study. They may have experienced the status loss that Link and Phelan (2001) in the context of power differential refer to since they had to reorganize their lives according to their child's needs, by reducing their work hours or not working, with the corresponding loss of earnings and effects on every aspect of family life and societal attitudes to them. Parents' evidence resonated with Lilley's (2013) assertion that inadequate state support and services for the developmentally disabled entails one parent being constantly available to advocate their child's needs. Their shock and worry made them unsure about how to proceed and about the overall future of their children, which accords with Sigman et al.'s (2006) findings.

Overall, the findings suggest an urgent need for emotional support and counselling, especially when there are further cutbacks to overstretched welfare services; as Ridge's (2013) study showed, reduced state financial support greatly impacted on most, but particularly on; those families with children with SEN ${ }^{7}$, whose educational, social and physical needs are not met.

This study was conducted in Greece during a period of austerity, financial cuts that affected all aspects of life, including education provision. Other countries with similar socio-political structures may not undergo austerity in the same way in comparative terms. However, the study offers a lens through which to view attitudes towards disability, stigmatisation, especially when resources are scarce.

This study has implications for professionals working with parents of children with ASD in Greece. The high level of perceived stigma experienced by parents, suggests the need to design interventions to improve public awareness/education about ASD and so reduce stigmatisation, and to improve access to the appropriate services. Professionals need to respect parents' beliefs and provide appropriate information on the causes and strategies to support ASD children and their parents. Future research investigating the needs and wellbeing of parents raising a child with ASD could add longitudinal studies including evaluations of the quality of the services provided to demonstrate how the needs of parents of children with ASD change over time, from the time of diagnosis and throughout the development of their child. This could also contribute to a better understanding of autism as a concept, what it is and what it entails and how it could be accepted as normal, but different, rather than an object of stigmatisation. 
Eirini Veroni is head teacher of a Special Educational Needs (SEN) school in Athens, Greece. Her BA is in Pedagogical studies from the National \& Kapodistrian University of Athens and she has a BA in Sociology from the Panteion University of Athens. Her MEd and PhD from Warwick University are in Special Educational

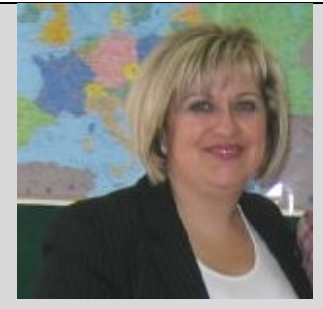
Needs. Her particular interest is the relationship between physical and economic support and the emotional feelings of support, control and empowerment that can develop through having a voice.

\section{References}

Autism Speaks, (2017). Autism and Health: A Special Report by Autism Speaks. Advances in understanding and treating the physical and mental health conditions that frequently accompany autism. Retrieved September 21, 2017 from: http://www.autismspeaks.org.

Avramidis, E. \& Kalyva, E. (2007). The influence of teaching experience and professional development on Greek teachers' attitudes towards inclusion. European Journal of Special Needs Education, 22(4), 367-389.

Beatson, J. (2008). Walk a mile in their shoes: Implementing familycentered care in serving children and families affected by Autism Spectrum Disorder. Topics in Language Disorders, 28(4), 309-322.

Beckman, P. (2002). Providing family- centered services. In M. Batshaw (Eds). A medical primer (pp. 683-691). Baltimore: Paul H. Brookes Publishing Company.

Benson, P. \& Karlof, K. (2009). Anger, Stress Proliferation, and Depressed Mood Among Parents of Children with ASD: A Longitudinal Replication. Journal of Autism and Developmental Disorders, 39, 350-362.

Braun, V. \& Clarke, V. (2013). Successful qualitative research a practical guide for beginners, London, SAGE Publications.

British Educational Research Association, (BERA), (2011). Ethical Guidelines for Educational Research, London: BERA.

Broady, T., Morse, C. \& Stoyles, G. (2015). Understanding carers' lived experience of stigma: the voice of families with a child on the autism spectrum. Health and Social Care in the Community, 25(1), 224-233.

Brobst, J., Clopton, J. \& Hendrick, S. (2009). Parenting children with autism spectrum disorders: The couple's relationship. Focus on Autism and Other Developmental Disabilities, 24(1), 38-49. 
Centre for Educational Research (KEE) (2009). The imprinting of the Greek educational system in terms of school units: Pupils with special educational Needs, Athens, KEE.

Cosser, C. (2005). Raising a Child with Attention Deficit Hyperactivity Disorder: A Parents' Perspective. Published Thesis: University of South Africa, 121-130.

Cramm, J. \& Nieboer, A. (2011). Psychological well-being of caregivers of children with intellectual disabilities: Using parental stress as a mediator factor. Journal of Intellectual Disabilities, 15(2), 101-113.

Dardas, L. (2014). Stress, coping strategies and quality of life among Jordanian parents of children with Autistic Disorder, Autism, 50 (12), 970976.

Dyson, L. (1997). Fathers and mothers of school-age children with developmental disabilities: Parental stress, family functioning and social support. American Journal on Mental Retardation, 102(3), 267-279.

Ekas, N., Lickenbrock, D. \& Whitman, T. (2010). Optimism, Social Support, and Well - Being in of Children with Autism Spectrum Disorder. Journal of Autism and Developmental Disorders, 40, 1274-1284.

Farrugia, D. (2009). Exploring stigma: Medical knowledge and the stigmatisation of parents of children diagnosed with autism spectrum disorder. Sociology of Health \& IIlness, 31(7), 1011-1027.

Gena, A., Kalogeropoulou, E., Mauropoulou, A., Nikolaou, A., Notas, S. \& Papageorgiou, B. (2006). Autism Spectrum. Trikala: Ella Publications.

Glover-Graf, N. (2011). Family adaptation across cultures towards a loved one who is disabled. In: I. Marini, N. Glover- Graf and M. Millington (Eds) Psychosocial aspects of disability: Insider perspectives and counseling strategies (pp. 169-194), New York: Springer Publishing Company.

Goffman, E. (1963). Stigma: Notes on the Management of Spoiled Identity. New York: Touchstone.

Goffman, E. (1986). Stigma: Notes on the Management of Spoiled Identity. New York: Touchstone.

Goffman, E. (2009). Stigma: Notes on the Management of Spoiled Identity. New York: Touchstone.

Gray, D. (1993). Perception of stigma: the parents of autistic children. Sociology of Health and IIIness, 15, 103-120. 
Gray, D. (2002). Everybody just freezes. Everybody is just embarrassed: felt and enacted stigma among parents of children with high functioning autism. Sociology of Health and IIIness, 24, 734-749.

Gray, D. (2003). Gender and coping: the parents of children with high functioning autism. Social Science \& Medicine, 56(3), 631-642.

Green, S. (2003). What do you mean 'what's wrong with her? Stigma and the lives of families of children with disabilities. Social Science \& Medicine, 57, (1361-1374).

Green, S., Davis, Ch., Karshmer, E. Marsh, P. \& Straight, B. (2005). Living stigma: The impact of labelling, separation, status loss, and discrimination in the lives of individuals with disabilities and their families. Sociological Inquiry, 75, (197-215).

Griffith, G., Hastings, R., Nash, S. \& Hill, C. (2010). Using matched groups to explore child behavior problems and maternal well-being in children with Down syndrome and autism. Journal of Autism and Developmental Disorders, 40(5), 610-619.

Guralnick, M., Hammond, M., Neville, B. \& Connor, R. (2008). The relationship between sources and functions of social support and dimensions of child -and parent- related stress. Journal of Intellectual Disability Research, 52(12), 1138-1154.

Hall, H., \& Graff, J. (2011). The relationships among adaptive behaviors of children with autism, family support, parenting stress, and coping. Issues in Comprehensive Pediatric Nursing, 34(1), 4-25.

Hartas, D. (2014). Parenting family policy, and children's well -being in an unequal society. Hampshire: Palgrave Macmillan.

Hassall, R., Rose, J. \& McDonald, J (2006). Parenting stress in mothers of children with an intellectual disability: The effects of parental cognitions in relation to child characteristics and family support. Journal of Intellectual Disability Research, 49 (6), 405-418.

Hayes, S. \& Watson, S. (2012). The Impact of parenting stress: A metaanalysis of studies comparing the experience of parenting stress in parents of children with and without Autism Spectrum Disorder. Journal of Autism and Developmental Disorder, 43, 629-642.

Heinman, T. (2002). Parents of Children with Disabilities: Resilience, Coping and Future Expectations. Journal of Development and Physical Disabilities, 14(2), 159-171. 
Hoogsteen, L. \& Woodgate, R. (2013). Centering autism within the family: A qualitative approach to autism and the family. Journal of Pediatric Nursing, 28 (2), 135-140.

Hope-West, A. (2011). Securing appropriate education provision for children with autism spectrum disorders. London \& Philadelphia: Jessica Kingsley Publishers.

Hutton, A. \& Caron, S. (2005). Experiences of families with children with autism in rural New England. Focus on Autism and Other Developmental Disabilities, 20(3), 180- 189.

Huws, J. \& Jones, R. (2010). 'They just seem to live their lives in their own little world': lay perceptions of autism. Disability \& Society, 25 (3), 331344.

Ingersoll, B. \& Hambrick, D. (2011). The relationship between the broader autism phenotype,child severity and stress and depression in parents of children with autism spectrum disorders. Research in Autism Spectrum Disorders, 5(1), 337-344.

James, A. (2005). The standardized child: Issues of openness. Objectivity and agency in promoting childhood health. Anthropological Journal of European Cultures, 13, 93-110.

Kalyva E. (2011). Autism: Educational and Therapeutic Approaches. London: Sage.

Kalyva E. (2013). Collaboration between parents of children with autism spectrum disorders and mental health professionals. Recent Advances in Autism Spectrum Disorders, 1(23), 521-555.

Karim, K., Cook, L. \& O'Reilly, M. (2012). Diagnosing autistic spectrum disorder in the age of austerity. Child: care, health and development, 40 (1), 115-123.

Keenan M., Dillenburger, K., Doherty, A., Byrne, J. \& Gallagher, S. (2007). Meeting the Needs of Families Living with Children Diagnosed with Autism Spectrum Disorder, (Final Report, pp. 184), University of Ulster: Coleraine, NI.

Kinnear, S., Link, B., Ballan, M. \& Fischbach, R. (2016). Understanding the experience of stigma for parents of children with autism spectrum disorder and the role stigma plays in families' lives. Journal of autism and developmental disorders, 46(3), 942-953.

Klar-Wolfond, E. (2006). The joy of autism: Redefining ability and quality of life. Retrieved October 20, 2014 from: http://www.joyofautism.com. 
Konstantareas, M. (1990). A psycho educational model for working with families of autistic children. Journal of Marital and Family Therapy, 16(1), 59-70.

Konstantareas, M. \& Homatidis, S. (1989). Assessing Child Symptom Severity and Stress in Parents of Autistic Children. The Journal of Child Psychology and Psychiatry, 30 (3), 459-470.

Lilley, R. (2013). Crying in the park: Autism stigma, school entry and maternal subjectivity. Studies in the Maternal, 5(2).

Link, B. \& Phelan, J. (2001). Conceptualizing stigma. Annual review of Sociology, 27(1), 363-385.

Link, B. \& Phelan, J. (2006). Stigma and its public health implications. The Lancet, 367(9509), 528.

Loukisas, T. \& Papoudi, D. (2016). Mothers' Experiences of children in the autistic spectrum in Greece: Narratives of development, education and disability across their blogs. International Journal of Disability, Development and Education, 63 (1) 64-78.

Lubetsky, M., Handen B. \& McGonigle, J. (2011). Autism Spectrum Disorder. New York: Oxford University Press.

Ludlow, A., Skelly, C. \& Rohleder, P. (2012). Challenges faced by parents of children diagnosed with Autism Spectrum Disorder. Journal of Health Psychology, 17(5), 702-711.

Makrygianni, M. \& Reed, P. (2010). Factors impacting on the outcomes of Greek intervention programmes for children with autism spectrum disorders. Research in Autism Spectrum Disorders, 4(4), 697-708.

Mavropoulou, S. (2007). Developing pilot befriending schemes for people with autism spectrum disorders in a region of Greece: Lessons from Practice. Child and Adolescent Mental Health, 12(3), 138 -142.

Meirsschaut, M., Royers, H. \& Warreyn, P. (2010). Parenting in families with a child with autism spectrum disorder and a typically developing child: Mothers' experiences and cognitions. Research in Autism Spectrum Disorders, 4, 661-669.

Miller, K., Morfidi, E. \& Soulis, S. (2013). Teachers' perceptions of Greek special education policies and practices. Journal of International Special Needs Education, 16(1), 53-65.

Ming, X. (2008). Autism Spectrum Disorders: Concurrent clinical disorders. Journal of Child Neurology, 23, 6-13. 
Ministry of Interior, Public Administration and Decentralization (2007). General Secretariat of Public Administration and Electronic Governance. General Directorate of Administrative Organization and Procedures. Citizen's with Disability Guide. Athens: National Printing.

Ministry of Education \& Religious Affairs (MNERA, 2008). The Special Educational Needs Policy. Athens: MNERA.

Montes, G. \& Halterman, J. (2007). Psychological functioning and coping among mothers of children with autism: A population - based study. Pediatrics, 119(5), 1040-1046.

Myers, B., Mackintosh, V. \& Goin-Kochel, R. (2009). My greatest joy and my greatest heart ache: Parents' own words on how having a child in the autism spectrum has affected their lives and their families' lives. Research in Autism Spectrum Disorders, 3(3), 670-684.

Papageorgiou, V. \& Kalyva, E. (2010). Self-reported needs and expectations of parents of children with autism spectrum disorders who participate in support groups. Research in Autism Spectrum Disorders, 4, 653-660.

Parish, S., Seltzer, M., Greenberg, J. \& Floyd, F. (2004). Economic implications of caregiving at midlife: Comparing parents with and without children who have developmental disabilities. Mental Retardation, 42(6), 413- 426.

Parker, R. \& Aggleton, P. (2003). HIV and AIDS-related stigma and discrimination: a conceptual framework and implications for action. Social Science \& Medicine 57(1), 13-24.

Patistea, E. \& Patistea-Tavoularea, N. (2009). Parents of children with ASD. An interdisciplinary approach to the management of their biopsychosocial problems. Nursing, 48 (1), 72-83.

Patton, M. (2002). Qualitative research and evaluation methods. London: Sage Publications.

Plant, M. and Sanders, R. (2007). Predictors of care-giver stress in families of pre-school-aged children with developmental disabilities. Journal of Intellectual Disability Research, 51(2), 109 -124.

Policy Department C: Citizens' Rights and constitutional Affairs, (2013). Country report on Greece for the study on member states' policies for children with disabilities. Belgium: European Union.

Prelock, P. \& Hutchins, T. (2008). The role of family - centered care in research supporting the social communication of children with autism spectrum disorder. Topics Language Disorders, 28(4), 323-339. 
Prelock, P. Beatson, J., Bitner, B., Broder, C. \& Ducker, A. (2003). Interdisciplinary assessment of young children with Autism Spectrum Disorder. Language, Speech and Hearing Services in Schools, 34, 194-202.

Punch, F. (2011). Introduction to Research Method in Education, London: Sage Publications.

Resch, J., Mireles, G., Benz, M., Grenwelge, C., Peterson, R. \& Zhang, D. (2010). Giving parents a voice: A qualitative study of the challenges experienced by parents of children with disabilities. Rehabilitation Psychology, 55 (2), 139.

Ridge, T. (2013). We are All in This Together? The Hidden Costs of Poverty, Recession and Austerity Policies on Britain's Poorest Children. Children \& Society, 27(5), 406 - 417.

Sigman, M., Spence, S. \& Wang, A. (2006). Autism from developmental and neuropsychological perspectives. Annual. Review of. Clinical Psychology, 2, 327-355.

Singer, G., Hornby, G., Park, J., Wang, M. \& Xu, J. (2012). Parent to parent peer support across the Pacific Rim. Journal of International Special Needs Education, 15(2), 89-106.

Stampoltzis, A., Papatrecha, V., Polychronopoulou, S. \& Mavronas, D. (2012). Developmental, familial and educational characteristics of a sample of children with Autism Spectrum Disorders in Greece. Research in Autism Spectrum Disorders, 6(4), 1297-1303.

Stein, R. \& Jessop, D. (2003). The impact on family scale revisited: further psychometric data. Journal of Developmental \& Behavioral Pediatrics, 24(1), 9-16.

Susman, J. (1994). Disability, stigma and deviance. Social Science \& Medicine. 38(1), 15-22.

Syriopoulou-Deli, C. (2010). A historical review of educational policy in Greece for children with pervasive developmental disorders, behavioural difficulties and other special educational needs. Review of European Studies, 2 (1), 1-14.

Syriopoulou-Deli, C., Cassimos, D., Tripsianis, G. \& Polychronopoulou, S. (2012). Teachers' perceptions regarding the management of children with autism spectrum disorders. Journal Autism Developmental Disorders, 42 (5), 755-768.

Tomanik, S., Harris, G. \& Hawkins, J. (2004). The relationship between behaviours exhibited by children with autism and maternal stress. Journal of Intellectual \& Developmental Disability, 29(1), 16-26. 
Twoy, R., Connolly, Ph. \& Novak, J. (2007). Coping strategies used by parents of children with autism. Journal of the American Academy of Nurse Practitioners, 19, 251-260.

Veroni, E. (2016). Examining services available to Greek parents of children with Autism Spectrum Disorders (ASD). COREJ: Cambridge Open-Review Educational Research e-Journal, 3, 98-110.

Wachtel, K. \& Carter, A. (2008). Reaction to diagnosis and parenting styles among mothers of young children with ASDs. Autism, 12(5), 575-594.

Wang, P. (2008). Effects of a parent training program on the interactive skills of parents of children with autism in China. Journal of Policy and Practice in Intellectual Disabilities, 5(2), 96-104.

Whitaker, P. (2002). Supporting families of preschool children with autism. Autism, 6(4) 411.

Whitehead, E. (2001). Teenage pregnancy: on the road to social death. International Journal of Nursing Studies, 38(4), 437-446.

Woodgate, L. Ateah, C. \& Secco, L. (2008). Living in a world of our own: The experience of parents who have a child with autism. Qualitative Health Research, 18(8), 1075.

\section{To cite this article:}

Veroni, E., 2019. The Social Stigma and the Challenges of Raising a Child with Autism Spectrum Disorders (ASD) in Greece. Exchanges: The Interdisciplinary Research Journal, 6(2), 1-29. Retrieved from: https://doi.org/10.31273/eirj.v6i2.200 
Appendix: Questionnaire for parents with children with ASD Personal Characteristics

1. What is your relationship to your child who has an autism spectrum disorder?

Mother $\square$ Father $\square$ Other (please describe):

2. What is your highest level of education completed?

$\Gamma$ Primary school graduate

$\Gamma$ High school graduate

$\Gamma$ Lyceum graduate

$\Gamma$ University graduate degree

Г Master or PhD degree

3. What is your marital status?

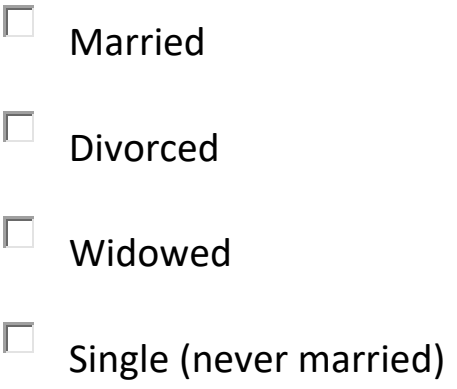

4. Have you (or your spouse) had to make any changes to your employment status in order to support your child with autism? (e.g. cut back on work hours, resign from your position)

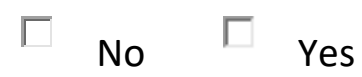

5. Does your child have siblings? Do any of these siblings have a medical condition or disability?

No Yes

How many have a medical condition or disability?

6. In what year was your child first diagnosed with an autism spectrum disorder? 
7. Has your child had any other mental health problems? Please tick as appropriate

Hearing problems $\sqsubset$ Speech \& Language problems
Balance \& Coordination problems $\sqcap \quad$ Feeding Problems
Clumsiness
Other:

What is your child's gender? $\square$ Male $\square$ Female

\section{Social Stigma Scale}

Which of these challenges would you say you have faced raising your child? Please tick as many as necessary:

$\begin{array}{lllll}\text { Bullying } & \Gamma \text { Prejudice } & & & \text { Stereotyping } \\ \text { Public } & \text { awareness } & \text { of } & \text { ASD }\end{array}$

Society labeling your child as "disobedient"


Exchanges: The Interdisciplinary Research Journal

\section{Open - Ended Interview Questions}

1. How do you feel your child is treated by others?

2. Have you experienced stigma and prejudice in society?

3. Do you keep your pain private and struggle to cope with everyday challenges?

4. Are your relationships with others difficult?

5. Has your child made friends with peers? 
Exchanges: The Interdisciplinary Research Journal

6. Do you feel that the only support/advice you get is from experts?

7. What type of social network (extended family, parent organizations/ groups, friends, church, other social clubs) do you find to be supportive of your child's disability?

8. What kind of support do you need to develop a social network for your child?

9. Do you get emotional support from other parents of children with ASD? What kind of external support do you need? 


\section{Endnotes}

${ }^{1}$ Autism Spectrum Disorders (ASD) refers to a group of developmental disorders (like autism and Asperger's syndrome) which affect sufferers' social and communication skills. They also display patterns or have restricted interests - also called pervasive developmental disorder (American Psychiatric Association, 2013). ASD is now so widespread that it has become a special needs category in Greek educational laws 1566 (1985), 2817 (2000) and 3699 (2008).

2 Applied Behaviour Analysis is a scientifically validated approach to understanding behaviour and how it is affected by the environment (Autism Speaks, 2017).

${ }^{3}$ See Special Education Law (L2817/2000, L3699/ 2008) and MNERA (2008) for details of the operation of the assessment, diagnosis, social and educational support of ASD children in Greece.

${ }^{4}$ Editor's note: Lyceum is a type of educational institution, common across Europe although not the UK, roughly equivalent to secondary/high school in level.

${ }^{5}$ See endnote 1.

${ }^{6}$ See endnote 1.

${ }^{7}$ According to the 1981 Education Act, 'SEN' in England refers to children receiving special education (Department for Education (DfE) 1981). Children with SEN are those who have "a learning difficulty which calls for special educational provision to be made for them" (DfE, 2014, p. 6). Communication, interaction, cognition, learning, emotional, social and behavioural difficulties, sensory and/or physical disabilities all come with the remit of SEN. 